\title{
Gender Considerations in Addiction: Implications for Treatment
}

\section{Kathryn Polak, B.S. ${ }^{1}$}

Nancy A. Haug, Ph.D. ${ }^{2}$

Haroldo E. Drachenberg, M.D. ${ }^{3}$

Dace S. Svikis, Ph.D. ${ }^{1, *}$

\author{
Address \\ ${ }^{*}, 1$ Virginia Commonwealth University, 806 W. Franklin St.P.0. Box 842018, Rich- \\ mond, VA 23284, USA \\ Email:dssvikis@vcu.edu \\ ${ }^{2}$ PGSP-Stanford Psy.D. Consortium, The Gronowski Center, Palo Alto University, \\ 5150 El Camino Real, C-24, Los Altos, CA 94022, USA \\ ${ }^{3} 6320$ Democracy Boulevard, Bethesda, MD 20817, USA
}

Published online: 7 July 2015

(C) Springer International Publishing AG 2015

This article is part of the Topical Collection on Substance Use Disorders

Keywords Gender · Addiction • Treatment · Pregnancy · Transgender · Pharmacogenomics

\section{Opinion statement}

Individuals with substance use disorders (SUD) are heterogeneous, making comprehensive assessment an essential part of treatment planning. Since a variety of pharmacological and psychosocial treatments are available, patient needs and characteristics, as well as substance-specific treatment options must be taken into account. In particular, clinicians should consider patient gender, as well as hormonal and other biological factors, when making treatment recommendations. Women are at greater risk for a variety of medical and psychosocial consequences, and may benefit from pharmacological and/or behavioral therapies that differ from those most beneficial for men. Pregnancy and gender identity also warrant special consideration. It is imperative that clinicians keep informed about new research findings that can guide tailoring of evidence-based treatments for men and women with SUD. Looking ahead, the field of pharmacogenomics offers additional promise for identifying the most effective pharmacotherapies for specific patients with SUD.

\section{Introduction}

Substance abuse is a major public health problem that costs the USA more than $\$ 700$ billion annually. In a national survey of persons $\geq 12$ years of age, 24.6 million
Americans (9.4\%) reported recent (past month) illicit drug use and 16.5 million (6.3\%) reported recent heavy drinking [1]. Gender differences exist in the 
development, course, and treatment of substance use disorders (SUD). While men are 1.9-2.2 times more likely to have SUD [2], women are more vulnerable to negative medical and psychosocial consequences of alcohol and other drugs $[3,4]$.

This paper describes recent studies of gender differences from the addiction field and their implications for the treatment of SUDs. Topics include the following: telescoping, stress and craving, hormones, and psychiatric comorbidity, as well as outcomes from recent studies of behavioral and pharmacological therapies for SUDs. Two special populations, pregnant women and transgender individuals, are discussed. Finally, interesting findings from the burgeoning field of pharmacogenomics are highlighted.

\section{Telescoping}

It was traditionally established that women progress from substance use to regular use to first treatment more rapidly than men for many substances including alcohol, cannabis, and opioids [5, 6]. However, recent reports on this phenomenon, known as telescoping, have been mixed [7]. Lewis and Nixon [8], for example, found no evidence of telescoping in the advancement from early alcohol use to alcohol dependence, but further progression to treatment remained more rapid with time to first treatment on average 4 years shorter for women than men. For opioids, one study found women continued to progress more rapidly than men from use to dependence [9]. Also, African-Americans progressed more quickly to opioid dependence than Caucasians. In contrast, Stoltman and colleagues [10], in a study of non-treatment-seeking heroin users, found that while females reported later age of onset of heroin use than males, there was no evidence of gender telescoping. Factors that may account for such varied results include narrowing of the gap between men and women in rates of alcohol and other substance use and dependence, as well as increased attention paid to more heterogeneous, often general population-based samples.

\section{Craving, stress, and hormones}

Research has shown that both stress and drug cue exposure increase drug craving and contribute to relapse for such drugs as cocaine, alcohol, and nicotine. Findings vary by gender, however, and may help inform future development of gender-specific treatment for SUD [11]. In animal studies, female rats exhibit longer HPA-axis activation and greater norepinephrine response to stress than male rats [12]. In laboratory studies, substance-abusing women show higher levels of anxiety, stress, and negative affect in response to stress and drug cues than substance abusing men (e.g., 13).

In alcohol dependent individuals, stress and cue reactivity combined have a negative effect on treatment outcomes [14]. Hartwell and Ray [15] found sexmoderated stress reactivity, with greater sensitivity to effects of stress-induced craving for alcohol and anxiety in female as compared to male heavy drinkers. For tobacco, Saladin et al. [16] found nicotine-dependent females responded to a stress/negative affect stimulus with more craving, stress and arousal as well as greater negative emotion than nicotine-dependent males. Wray and colleagues [17] reported similar findings in a study conducted in the natural environment. 
Ovarian hormones may contribute to sexual differentiation in addiction, mediating response to substance use [18]. Recent studies of the relationship between hormones and cocaine found that estrogen plays an important role in the transition from recreational drug use to cocaine dependence [19]. Specifically, using real-time exposures to drug cues and drug use, Kennedy and colleagues [20] found that women were more sensitive than men to such exposures. Further, Perry, and colleagues [21] found estradiol affected cocaine self-administration only in females, suggesting pubertal estradiol may be a necessary, but not sufficient, factor in later development of sensitivity to this hormone.

This research suggests hormonal factors may inform development of strategies to reduce the abuse liability of cocaine. Broderick and Malave [22], for example, found caffeine blocked cocaine-promoted changes in the estrus cycle, suggesting adenosine antagonizers have neuroprotective properties. Also, Fox and colleagues [23] showed progesterone's cravingreducing effects were moderated by both gender and type of environmental cue exposure; cocaine-dependent females who were administered progesterone experienced a diminished negative emotion response to stress compared to controls. These data indicate endocrinology contributes to a person's risk for developing SUD. Recent findings underscore our need to focus on female populations, particularly those experiencing fluctuations and shifts in hormone levels such as puberty, pregnancy, and during menopause.

Neuroimaging studies have added to our understanding of sex differences in brain response to cue reactivity in cocaine and other drug users. In a recent review, Andersen and colleagues [24] found cocaine-using women had greater cerebral blood flow in the amygdala, insula, and orbitofrontal cortex than cocaine-using men. Brain activation in response to stressful imagery was also greater in the posterior cingulate, insula, and inferior frontal cortex of females as compared to males.

Potenza and colleagues [25•] examined neural correlates of stress and drug cue reactivity in a sample of cocaine-dependent men and women and a group of social drinking controls using functional MRI. They found a three-way interaction of gender, substance use disorder, and stimulus type (stress or drug cue). First, while both cocaine-dependent males and females showed activation in the amygdala, striatum, and insula, activation was in response to stress cues for women and drug cues for men. Second, males and females reported positive correlations between brain activation and subjective craving. For women, however, this was seen in the midbrain, hippocampus, ventrolateral prefrontal cortex, and thalamus. In contrast, for men, it was seen in the hippocampus, insula, and the dorsolateral, dorsomedial, temporal, and parietal cortices.

With no current FDA-approved pharmacological treatment for cocaine, attention has turned to guanfacine $\mathrm{HCl}$, an alpha2 adrenergic agonist that blocks stress-induced reinstatement of cocaine self-administration in rats [26]. In cocaine-dependent men and women, Fox and colleagues [27] found guanfacine produced gender-specific effects, with stress dampening, as well as reductions in cocaine and alcohol craving, anxiety, and negative emotion, only in women. Both genders, however, showed reduced stress and cue-induced 
craving for nicotine and decreased systolic blood pressure [27].

Taken together, these gender differences have important treatment implications. Cocaine-dependent women may benefit more from stress-reduction therapies that specifically target craving, while cocaine-dependent men might profit more from CBT or 12-step recovery programs. Moreover, smoking cessation efforts for women should include development of coping skills in response to stress cues.

\section{Treatment engagement, retention, and outcomes}

In 1993, NIH mandated that both men and women be included in clinical trials and gender be included in outcome analyses [28]. At present, more than half of clinical-research participants in NIH-supported studies are women. Increased knowledge about the role of sex and gender in medicine has prompted the NIH to spearhead similar policies in preclinical studies, requiring a balance of male and female cells and animals [29]. In the field of addiction, the literature is filled with studies of gender differences in substance abuse treatment. Contradictory findings, however, have generated skepticism and debate. Inconsistent results are often attributed to methodological issues (e.g., small sample sizes) as well as differences in patient (psychiatric comorbidities, specific substance(s) of abuse) and treatment (methadone maintenance, residential) characteristics [30].

A recent review of SUD treatment entry, retention, and outcome data for women shed new light on this issue [31]. While women were less likely to enter treatment than men, gender did not generally predict treatment retention and related outcomes. In addition, many studies limited analyses to gender as a dichotomous predictor of treatment outcome. An alternative is to examine gender as a stratification variable, so that other risk factors can be studied. An analysis of gender-related translational studies from the NIDA Clinical Trials Network (CTN) found comorbid psychiatric disorders and trauma histories in women often complicated drug abuse treatment outcomes and added to psychosocial risk [32].

While social and economic factors continue to fuel debate about the need for gender-specific SUD treatment for women, researchers continue to find gender-specific drug treatment services generally yield better outcomes [33]. Greenfield et al. [34] found greater endorsement of positive aspects of therapy (e.g., felt safety and honesty) in women-only as compared to mixed-gender group therapy. Women-only therapy participants also reported enhanced support and greater focus on gender relevant topics than mixed-gender group women. Similarly, Evans et al. [35] found women-only group therapy was associated with longer enduring benefits to drug-dependent mothers than mixed-gender therapy, and Kissin et al. [36] reported women in gendersensitive treatment programs had better legal outcomes (i.e., fewer arrests) than those in traditional programs.

In an examination of national SUD treatment availability from 2002 to 2010, Longinaker and colleagues [33] reported a decline in specific programs for women ( $38 \%$ in 2002 to $32 \%$ in 2010, $p<.001$ ). Geographic disparities were found for many components of women-centered care, and treatment service availability was unrelated to treatment need. 


\section{Psychiatric comorbidity}

Men and women with SUDs present for treatment with different medical, psychiatric, and psychosocial co-morbidities, which in turn can impact treatment outcomes [37]. Previous research found women with SUD have higher rates of mental disorders including depression, anxiety, eating disorders, and trauma than their male counterparts [38]. A recent review found comorbid depression had more detrimental impact on SUD treatment outcomes for women as compared to men [39].

A multi-site clinical trial of the Job Seekers' Workshop (JSW) found women in outpatient SUD treatment reported higher rates of physical and sexual abuse as well as suicidality than men [40]. Severity of mental health symptoms, however, did not differ by gender, and lifetime trauma did not predict employment outcomes. Another recent study showed that trauma-informed treatment led to reductions in trauma symptom severity for both men and women [41].

Using the National Survey on Drug Use and Health data (2005-2010), Chen and colleagues [42•] found unmet treatment needs were more likely to be reported by participants with comorbid SUD and major depressive episode (MDE), regardless of gender. However, males with SUD and MDE were more likely to be treated in the ER and use inpatient medical services than females with those conditions. In contrast to previous studies, men and women in this national community-based sample reported similar barriers to treatment and comparable levels of perceived social stigma and negative attitudes.

\section{Pharmacotherapy and psychogenomics}

The development and testing of new and more effective pharmacotherapies for the treatment of SUDs continues to be a national priority, as there is considerable variability in efficacy for current medications. Unfortunately, despite the NIH Office of Research on Women's Health expectation that researchers consider sex and gender in the development and testing of medications, gendersensitive treatment effects are often not reported. Investigators cite small sample sizes and insufficient power as justification [43], contributing at times to lower treatment efficacy for women as compared to men [44].

To overcome sample size limitations, researchers have begun to analyze aggregate data from multiple randomized clinical trials. DeVito and colleagues [45], for example, compared treatment outcomes for cocainedependent males and females across five clinical trials of behavioral and pharmacological (disulfiram) treatments. While they found no gender differences in behavioral therapy outcomes, disulfiram was found to be less effective in women as compared to men.

Efforts to identify more effective pharmacotherapies for the treatment of SUDs may also be facilitated by advances in pharmacogenomics, the study of how genetic variation affects drug response, drug efficacy, and adverse drug effects. In psychiatry, pharmacogenomics is focused on genetic variation in metabolizing enzymes, transporters, and receptor targets with the goal of improving treatment outcomes. 
Male smokers have consistently been found to respond better to nicotine replacement therapy (NRT) than female smokers [46]. Women may also respond less favorably to bupropion. Men report greater relief of craving from NRT than women, suggesting the importance of physiological dependence to their addiction [47]. Women report greater cessation fatigue than men [48] in pharmacotherapy trials. A recent review of gender differences in inability to quit smoking affirmed that while men tended to smoke for the reinforcing properties of nicotine, women smoked to regulate negative affect and stress [49]. Since most FDA-approved medications for smoking cessation target the nicotinic acetylcholine (nAChR) system, this makes them less optimal for women, affirming the need for gendersensitive treatments.

Pharmacogenetic studies have focused on identification of genes that confer risk for development of nicotine dependence and may guide development of more effective treatments for smoking cessation. While many studies are limited by small sample size and homogeneous groups of participants, recent findings support continued work in this area. A metaanalysis by the Pharmacogenetics of Nicotine Addiction Treatment Consortium (PNAT), found effects of NRT for smoking cessation were moderated by genetic variants of CHRNA5 [50]. Similarly, Chen and colleagues [51] found the nicotine metabolizing gene (CYP2A6) moderated effect of NRT on smoking cessation, with relapse delayed in rapid but not slow metabolizers. Also, the impact of NRT on continuous abstinence was moderated by the combined genetic risks from CYP2A6 and CHRNA5. Recent studies looking at gender as a potential moderator of pharmacogenomic effects in smoking cessation have yielded mixed results [52]. While some research found genotype effects on treatment response in women but not men (e.g., 53, 54), others found no evidence of sex differences (e.g., 55, 56). Sex hormones and their impact on dopamine (DA) reward pathways must also be considered and add complexity. For example, a recent laboratory study of IV nicotine administration found female smokers tested in the luteal as compared to the follicular phase of their cycle reported less withdrawal, less post-session craving, and diminished subjective drug effects [57].

The efficacy of naltrexone and other FDA-approved medications for treatment of AUDs has been modest, with substantive variability in outcomes. This prompted research on predictors of differential treatment response, including genetic factors. For naltrexone, which acts as a competitive opioid antagonist, much research has focused on the mu-opioid receptor gene (OPRM1). In a meta-analysis, Chamorro et al. [58] found the G allele of the A118G polymorphism of OPRM1 moderated the effect of naltrexone in alcohol-dependent individuals, with lower relapse rates than comparison groups.

Sex differences in response to opioid receptor antagonists have also been found, though results vary. Women tend to experience more adverse 
subjective effects and have better treatment outcomes than men (e.g., 59). Also, naltrexone was found to reduce the stimulating effects of alcohol in women but not men [60].

In a laboratory study of naltrexone with non-dependent drinkers, Setiawan and colleagues [61] found gender and genotype differences, with naltrexone reducing positive subjective effects of alcohol in females and in those with the A118G polymorphism of OPRM1. These subjective effect differences, however, did not translate into lower rates of alcohol selfadministration. Findings, while preliminary, illustrate the importance of testing for gender effects in clinical trials of pharmacogenomics.

\section{Pregnant women: special considerations}

Prenatal substance use increases risk for adverse maternal, fetal, and infant outcomes and constitutes a major public health problem. Negative consequences do not end at birth, with longitudinal studies continuing to find that children and adolescents exposed to drugs in utero are more likely to experience a range of physical and neurodevelopmental problems [62]. While negative consequences of heavy drinking during pregnancy such as FAS and FASD are well-known [63], a recent meta-analysis found that even moderate drinking during pregnancy was associated with such childhood problems as trouble following classroom directions, unwillingness to share and impatience while waiting for adult attention [64].

Prenatal cigarette smoking is the most important preventable risk factor for adverse pregnancy outcomes, yet $13 \%$ of pregnant women continue to smoke [65]. NRT is still rarely prescribed during pregnancy, due to concerns over fetal safety. One recent study found similar rates of major congenital anomalies for pregnant women prescribed NRT and those who continued to smoke (35 and $27 \%$, respectively) [66]. Findings must be interpreted with caution, however, as confounding factors such as intensity of smoking were not assessed.

Over the past 15 years, marijuana, methamphetamine, and prescription opioid use have increased dramatically among pregnant women [67•]. Marijuana is the most frequently used illicit drug prenatally, and it may be more prevalent than tobacco during pregnancy in some communities [68]. Although the effects of marijuana on neonatal outcome are inconclusive [69], infant growth restriction and low birth weight have been associated with prenatal use, particularly in mid-to late pregnancy [70]. Recent studies on prenatal use of methamphetamines found high rates of medical and psychiatric comorbidity, including low birth weight, preterm delivery, intrauterine fetal death, and abruption [71], and longitudinal studies report cognitive problems in children with in-utero exposure to methamphetamines [72]. Prescription opioid use among pregnant women has increased substantially over the past two decades [73], with a parallel rise in neonatal opioid exposure and neonatal abstinence syndrome (NAS) [74].

Methadone, an opioid agonist, has long been the gold standard in opioid substitution therapy for pregnant opioid-dependent women. Strong evidence for the effectiveness of methadone treatment in pregnancy includes high treatment retention, decreased illicit opioid use, and enhanced prenatal care utilization $[75,76]$. Nevertheless, methadone is associated with increased incidence 
of NAS. More recently, buprenorphine, a partial opioid agonist, has emerged as an alternative to methadone, showing a reduction in the duration and severity of NAS [77]. A combination of buprenorphine plus the opioid antagonist naloxone has also been used to treat pregnant women, demonstrating no adverse outcomes [78, 79], less severe NAS, and shorter hospital stays compared to methadone [80]. While more research is needed, methadone may be the treatment of choice for long-standing poly-substance abuse whereas buprenorphine may be the preferred treatment for prescription opioid abusers or those with shorter histories of dependence [81].

At present, there is no FDA-approved medication for infants with NAS; oral morphine and methadone are often used and buprenorphine shows potential but is in need of further research [82]. NAS severity is not related to maternal opioid dose [77], and infants with NAS often require care in the NICU and extended hospital stays [83]. One promising area is pharmacogenomics where recent studies demonstrated the importance of the OPRM1 gene in opioid addiction and NAS. Specifically, variants in the OPRM1 and COMT genes were associated with shorter hospital stays and less need for treatment among infants with NAS [84•]. In addition, hypermethylation within the OPRM1 promoter was associated with worse NAS outcomes [85].

For pregnant women who are not opioid-dependent, empirically supported psychosocial and behavioral substance abuse treatment programs have been developed to address substance use, trauma and co-occurring disorders in both individual and group formats (see $86 \bullet \bullet$ for comprehensive review). The American Society for Addiction Medicine recommends culturally sensitive treatment consisting of a family-centered approach, case management, childcare, transportation, interdisciplinary collaboration, mental health services, prenatal care and reproductive counseling [87]. Contingency management (i.e., financial or motivational incentive) approaches have shown the most promising results for improving treatment retention and access to prenatal services [88] as well as decreasing tobacco use [89]. For many women who use substances, pregnancy may be a window of opportunity to eliminate drugs, reduce risky behaviors, improve psychological functioning, and adopt an overall healthier lifestyle.

Eighteen states consider prenatal substance use to be child abuse under civil child-welfare statutes, and one state allows assault charges to be filed against a pregnant woman for using certain substances. However, treatment for substance use problems during pregnancy is more effective than legal measures and highly preferred over criminalization and incarceration to improve maternal health and long-term outcomes $[87,90]$. Even though the intention of such legislation is to encourage pregnant women with SUD to make positive changes, limited treatment options make access to care problematic and hinder recovery efforts for many pregnant drug-dependent women.

\section{Transgender individuals: special considerations}

While this article is focused on gender differences between males and females in addiction, transgender individuals may not conform to traditional gender identity based on a binary system that attributes social characteristics to sexed anatomy. As such, it is important to consider the 
special treatment needs of individuals along this spectrum of gender nonconformity, male-to-female transgender women (transwomen) and female-to-male transgender men (transmen).

Transgender individuals encounter high rates of minority stressors including physical and sexual violence, discrimination, gender-related victimization, and stigma [91]. Research indicates that transgender people are often denied access to comprehensive medical care and experience harassment in medical settings because of their gender identity [92]. The minority stress model as applied to transgender populations suggests that these adverse experiences have serious effects on the mental health of transgender people, as evidenced by high rates of suicidal ideation, suicide attempts, and substance use [91, 93].

Rates of alcohol and other substance use are disproportionately higher among transgender persons relative to cisgender counterparts [94]. Transgender female youth (age 16-24) are at high risk for polysubstance abuse and HIV infection with comorbid concerns such as PTSD, gender-related discrimination, psychological distress, and parental drug and alcohol problems [95]. Transwomen, in particular, face victimization, homeless, and risk for HIV infection [96]. Transwomen often report substance use within the context of anal intercourse, with a strong association between methamphetamine and HIV infection [94]. This suggests that treatment providers should attend to the relationship between sexual activity and methamphetamine use among transwomen [97]. Medical complications (e.g., HIV, hepatitis B and C) and potential side effects of combining hormone therapy with illicit substances, particularly alcohol, should also be assessed [98].

Transgender competence in mainstream settings includes the following: (1) assessment of constructions of gender during the intake process; (2) respect for how patients would like to be addressed with regard to gender (e.g., pronouns and name); (3) an evaluation of gender identity experiences (e.g., conflict, abuse) and impact on mental health and substance use (see 99); and (4) gender sensitivity training [98]. Psychiatrists should consider that those undergoing a gender transition may be reluctant to disclose symptoms of mental illness or substance use, due to concerns about jeopardizing hormone therapy or surgery $[100 \bullet \bullet$. Providers should not require patients to have resolved their gender identity concerns but rather assist them in forming a treatment plan which integrates substance use problems and gender identity issues (see $[100 \bullet \bullet]$ for a comprehensive protocol to address transgender mental health).

\section{Conclusion}

Gender differences are found in the development, course, and treatment of SUD, with women often at greater risk than men. Additionally, certain populations appear to be particularly vulnerable to substance use disorders and subsequent consequences, including pregnant women and transgender individuals. Recent findings affirm that gender is an important variable and that men and women may benefit from different behavioral and/or pharmacological treatments for SUD. Looking ahead, pharmacogenomics may provide additional opportunities to identify medications most likely to be effective for a particular patient. 


\section{Conflict of Interest}

Kathryn Polak, Nancy A. Haug and Dace S. Svikis declare that they have no conflict of interest.

Haroldo E. Drachenberg reports lecture honoraria from AssureRx Health, Inc. unrelated to this article.

\section{Human and Animal Rights and Informed Consent}

This article does not contain any studies with human or animal subjects performed by any of the authors.

\section{References and Recommended Reading}

Papers of particular interest, published recently, have been highlighted as:

- Of importance

-• Of major importance

1. National Survey of Drug Use and Health. National Institute on Drug Abuse. 2013. Retrieved from http:// www.drugabuse.gov/related-topics/trends-statistics on May 13, 2015.

2. Compton WM, Thomas YF, Stinson FS, et al. Prevalence, correlates, disability, and comorbidity of DSMIV drug abuse and dependence in the United States: results from the National Epidemiologic Survey on Alcohol and Related Conditions. Arch Gen Psychiatry. 2007;64(5):566-76.

3. Moran-Santa Maria MM, Flanagan J, Brady K. Ovarian hormones and drug abuse. Curr Psychiatry Rep. 2014;16(11):511.

4. Bobzean SAM, DeNobrega AK, Perrotti LI. Sex differences in the neurobiology of drug addiction. Exp Neurol. 2014;259:64-74.

5. Brady KT, Randall CL. Gender differences in substance use disorders. Psychiatr Clin N Am. 1999;22(2):24152.

6. Hernandez-Avila CA, Rounsaville BJ, Kranzler HR. Opioid-, cannabis- and alcohol-dependent women show more rapid progression to substance abuse treatment. Drug Alcohol Depend. 2004;74:265-72.

7. Keyes KM, Martins SS, Blanco C. Telescoping and gender differences in alcohol dependence: new evidence from two national surveys. Am J Psychiatry. 2010;167(8):969-76.

8. Lewis B, Nixon SJ. Characterizing gender differences in treatment seekers. Alcohol Clin Exp Res. 2014;38(1):275-84.

9. Sartor CE, Kranzler HR, Gelernter J. Rate of progression from first use to dependence on cocaine or opioids: a cross-substance examination of associated demographic, psychiatric, and childhood risk factors. Addict Behav. 2014;39(2):473-9.

10. Stoltman JJ, Woodcock EA, Lister JJ, et al. Exploration of the telescoping effect among not-in-treatment, intensive heroin-using research volunteers. Drug Alcohol Depend. 2015;148:217-20.

11. Moller FG. Sex, stress, and drug cues in addiction. Am J Psychiatry. 2012;169(4):351-3.

12. Heinsbroek RP, van Haaren F, Feenstra MG, et al. Sex differences in the effects of inescapable footshock on central catecholaminergic and serotonergic activity. Pharmacol Biochem Behav. 1990;37(3):539-50.

13. Fox HC, Sinha R. Sex differences in drug-related stresssystem changes: implications for treatment in substance-abusing women. Harv Rev Psychiatry. 2009;17(2):103-19.

14. Sinha R, Fox HC, Hong KI, et al. Effects of adrenal sensitivity, stress- and cue-induced craving, and anxiety on subsequent alcohol relapse and treatment outcomes. Arch Gen Psychiatry. 2011;68(9):942-52.

15. Hartwell EE, Ray LA. Sex moderates stress reactivity in heavy drinkers. Addict Behav. 2013;38(11):2643-6.

16. Saladin ME, Gray KM, Carpenter MJ, et al. Gender differences in craving and cue reactivity to smoking and negative affect/stress cues. Am J Addict. 2012;21(3):210-20.

17. Wray JM, Gray KM, McClure EA, et al. Gender differences in responses to cues presented in the natural environment of cigarette smokers. Nicotine Tob Res. 2015;17(4):438-42.

18. Hudson A, Stamp JA. Ovarian hormones and propensity to drug relapse: a review. Neurosci Biobehav Rev. 2011;35(3):427-36.

19. Ramôa CP, Doyle SE, Naim DW, et al. Estradiol as a mechanism for sex differences in the development of an addicted phenotype following extended access cocaine self-administration. Neuropsychopharmacology. 2013;38(9):1698-705.

20. Kennedy AP, Epstein DH, Phillips KA, et al. Sex differences in cocaine/heroin users: drug-use triggers and 
craving in daily life. Drug Alcohol Depend.

2013;132(1-2):29-37.

21. Perry AN, Westenbroek C, Becker JB. Impact of pubertal and adult estradiol treatments on cocaine self-administration. Horm Behav. 2013;64(4):573-8.

22. Broderick PA, Malave LB. Cocaine shifts the estrus cycle out of phase and caffeine restores it. J Caffeine Res. 2014;4(4):109-13.

23. Fox HC, Sofuoglu M, Morgan PT, et al. The effects of exogenous progesterone on drug craving and stress arousal in cocaine dependence: impact of gender and cue type. Psychoneuroendocrinology.

2013;38(9):1532-44.

24. Andersen ML, Sawyer EK, Howell LL. Contributions of neuroimaging to understanding sex differences in cocaine abuse. Exp Clin Psychopharmacol.

2012;20(1):2-15.

25. Potenza MN, Hong KI, Lacadie CM, et al. Neural correlates of stress-induced and cue-induced drug craving: influences of sex and cocaine dependence. Am J Psychiatry. 2012;169(4):406-14.

This article presents neuroimaging data on physiological sex differences and SUDs; specifically, using functional MRI, investigators found sex differences regarding neural correlates of craving in cocaine dependent and recreational drinking (control group) individuals.

26. Erb S, Hitchcott PK, Rajabi H, et al. Alpha-2 adrenergic receptor agonists block stress-induced reinstatement of cocaine seeking. Neuropsychopharmacology. 2000;23(2):138-50.

27. Fox HC, Morgan PT, Sinha R. Sex differences in guanfacine effects on drug craving and stress arousal in cocaine-dependent individuals.

Neuropsychopharmacology. 2014;39(6):1527-37.

28. U.S. Food and Drug Administration. Guideline for the study and evaluation of gender differences in the clinical evaluation of drugs; notice. Fed Regist. 1993;58(139):39406-16.

29. Clayton JA, Collins FS. Policy: NIH to balance sex in cell and animal studies. Nature. 2014;509:282-3.

30. Levine AR, Lundahl LH, Ledgerwood DM, et al. Gender-specific predictors of retention and opioid abstinence during methadone maintenance treatment. J Subst Abuse Treat. 2015.

31. Greenfield SF, Brooks AJ, Gordon SM, et al. Substance abuse treatment entry, retention, and outcome in women: a review of the literature. Drug Alcohol Depend. 2007;86(1):1-21.

32. Greenfield SF, Rosa C, Putnins SI, et al. Gender research in the National Institute on Drug Abuse National Treatment Clinical Trials Network: a summary of findings. Am J Drug Alcohol Abuse. 2011;37(5):301-12.

33. Longinaker N, Appel L, Terplan M. Availability of womencentered drug treatment services: an analysis of NSSATS 2002-2010. Drug Alcohol Depend. 2015;146, e184.

34. Greenfield SF, Cummings AM, Kuper LE, et al. A qualitative analysis of women's experiences in single-gender versus mixed-gender substance abuse group therapy. Subst Use Misuse. 2013;48(9):750-60.

35. Evans E, Li L, Pierce J, et al. Explaining long-term outcomes among drug dependent mothers treated in women-only versus mixed-gender programs. J Subst Abuse Treat. 2013;45(3):293-301.

36. Kissin WB, Tang Z, Campbell KM, et al. Gendersensitive substance abuse treatment and arrest outcomes for women. J Subst Abuse Treat.

2014;46(3):332-9.

37. Greenfield SF, Back SE, Lawson K, et al. Substance abuse in women. Psychiatr Clin N Am.

2010;33(2):339-55.

38. Center for Substance Abuse Treatment. Substance abuse treatment for persons with co-occurring disorders. Treatment Improvement Protocol (TP). Substance Abuse and Mental Health Services Administration. 2005. No. 42 (DHHS Publication No. (SMA) 053992).

39. Weinberger AH, Mazure CM, Morlett A, et al. Two decades of smoking cessation treatment research on smokers with depression: 1990-2010. Nicotine Tob Res. 2013;15(6):1014-31.

40. Keyser-Marcus L, Alvanzo A, Rieckmann T, et al. Trauma, gender, and mental health symptoms in individuals with substance use disorders. J Interpers Violence. 2015;30(1):3-24.

41. Cosden M, Larsen JL, Donahue MT, et al. Trauma symptoms for men and women in substance abuse treatment: a latent transition analysis. J Subst Abus Treat. 2015;50:18-25.

42. Chen LY, Strain EC, Crum RM, et al. Gender differences in substance abuse treatment and barriers to care among persons with substance use disorders with and without comorbid major depression. J Addict Med. 2013;7(5):325-34.

Using national survey data collected over a five-year period, this study illustrates the nuanced relationship between gender and comorbid substance use disorders and major depression.

43. Marrocco A, Stewart DE. We've come a long way, maybe: recruitment of women and analysis of results by sex in clinical research. J Womens Health Gend Based Med. 2001;10(2):175-9.

44. Nieuwenhoven L, Klinge I. Scientific excellence in applying sex- and gender-sensitive methods in biomedical and health research. J Womens Health (Larchmt). 2010;19(2):313-21.

45. DeVito EE, Babuscio TA, Nich C, et al. Gender differences in clinical outcomes for cocaine dependence: randomized clinical trials of behavioral therapy and disulfiram. Drug Alcohol Depend. 2014;145:156-67.

46. Perkins KA, Scott J. Sex differences in long-term smoking cessation rates due to nicotine patch. Nicotine Tob Res. 2008;10(7):1245-50.

47. Schnoll RA, Patterson F. Sex heterogeneity in pharmacogenetic smoking cessation clinical trials. Drug Alcohol Depend. 2009;104:S94-9. 
48. Liu X, Li R, Lanza ST, et al. Understanding the role of cessation fatigue in the smoking cessation process. Drug Alcohol Depend. 2013;133(2):548-55.

49. Verplaetse TL, Weinberger AH, Smith PH, et al. Targeting the noradrenergic system for gendersensitive medication development for tobacco dependence. Nicotine Tob Res. 2015;17(4):48695.

50. Bergen AW, Javitz HS, Krasnow R, et al. Nicotinic acetylcholine receptor variation and response to smoking cessation therapies. Pharmacogenet Genomics. 2013;23:94-103.

51. Chen LS, Bloom AJ, Baker TB, et al. Pharmacotherapy effects on smoking cessation vary with nicotine metabolism gene (CYP2A6). Addiction. 2014;109(1):128-37.

52. Herman AI, DeVito EE, Jensen KP, et al. Pharmacogenetics of nicotine addiction: role of dopamine. Pharmacogenomics. 2014;15(2):221-34.

53. Swan GE, Valdes AM, Ring HZ, et al. Dopamine receptor DRD2 genotype and smoking cessation outcome following treatment with bupropion SR. Pharmacogenomics J. 2005;5(1):21-9.

54. David SP, Munafo MR, Murphy MFG, et al. Genetic variation in the dopamine $\mathrm{D} 4$ receptor (DRD4) gene and smoking cessation: follow-up of a randomised clinical trial of transdermal nicotine patch. Pharmacogenomics J. 2008;8:122-8.

55. Leventhal AM, David SP, Brightman M, et al. Dopamine $\mathrm{D} 4$ receptor gene variation moderates the efficacy of bupropion for smoking cessation.

Pharmacogenomics J. 2012;12(1):86-92.

56. Gold AB, Wileyto EP, Lori A, et al. Pharmacogenetic association of the galanin receptor (GALR1) SNP rs2717162 with smoking cessation. Neuropsychopharmacology. 2012;37(7):1683-8.

57. Herman AI, Jatlow PI, Gelernter J, et al. COMT Val158Met modulates subjective responses to intravenous nicotine and cognitive performance in abstinent smokers. Pharmacogenomics J. 2013;13(6):490-7.

58. Chamorro AJ, Marcos M, Miron-Canelo JA, et al. Association of mu-opioid receptor (OPRM1) gene polymorphism with response to naltrexone in alcohol dependence: a systematic review and meta-analysis. Addict Biol. 2012;17:505-12.

59. King AC, Cao D, Zhang L, O'Malley SS. Naltrexone reduction of long-term smoking cessation weight gain in women but not men: a randomized controlled trial Biol Psychiatry. 2013;73:924-30.

60. Tidey JW, Monti PM, Rohsenow DJ, et al. Moderators of naltrexone's effects on drinking, urge, and alcohol effects in non-treatment-seeking heavy drinkers in the natural environment. Alcohol Clin Exp Res. 2008;32(1):58-66.

61. Setiawan E, Pihl RO, Cox SM, et al. The effect of naltrexone on alcohol's stimulant properties and selfadministration behavior in social drinkers: influence of gender and genotype. Alcohol Clin Exp Res. 2011;35(6):1134-41.
62. Sithisarn T, Granger DT, Bada HS. Consequences of prenatal substance use. Int J Adolesc Med Health. 2012;24(2):105-12.

63. Bailey BA, Sokol RJ. Pregnancy and alcohol use: evidence and recommendations for prenatal care. Clin Obstet Gynecol. 2008;51(2):436-44.

64. Flak AL, Su S, Bertrand J, et al. The association of mild, moderate, and binge prenatal alcohol exposure and child neuropsychological outcomes: a meta-analysis. Alcohol Clin Exp Res. 2014;38(1):214-26.

65. Centers for Disease Control and Prevention. Preventing smoking and exposure to secondhand smoke before, during, and after pregnancy. Department of Health \& Human Services; 2015. Accessed 20 May 2015. Available from: http://www.cdc.gov/nccdphp/publications/ factsheets/prevention/pdf/smoking.pdf.

66. Dhalwani NN, Szatkowski L, Coleman T, et al. Nicotine replacement therapy in pregnancy and major congenital anomalies in offspring. Pediatrics.

2015;135(5):859-67.

67. McHugh RK, Wigderson S, Greenfield SF. Epidemiology of substance use in reproductive-age women. Obstet Gynecol Clin N Am. 2014;41(2):177-89.

This study describes the dramatic rise in marijuana, methamphetamine and prescription opioid use during pregnancy and discusses the clinical and economic impact of such epidemiological trends.

68. Beatty JR, Svikis DS, Ondersma SJ. Prevalence and perceived financial costs of marijuana versus tobacco use among urban low-income pregnant women. J Addict Res Ther. 2012;3(4)

69. van Gelder MM, Reefhuis J, Caton AR, et al. Characteristics of pregnant illicit drug users and associations between cannabis use and perinatal outcome in a population-based study. Drug Alcohol Depend. 2010;109(1-3):243-7.

70. El Marroun H, Tiemeier H, Steegers EA, et al. Intrauterine cannabis exposure affects fetal growth trajectories: the Generation R Study. J Am Acad Child Adolesc Psychiatry. 2009;48(12):1173-81.

71. Gorman MC, Orme KS, Nguyen NT, et al. Outcomes in pregnancies complicated by methamphetamine use. Am J Obstet Gynecol. 2014;211(4):429.e1-7.

72. Diaz SD, Smith LM, LaGasse LL, et al. Effects of prenatal methamphetamine exposure on behavioral and cognitive findings at 7.5 years of age. J Pediatr. 2014;164(6):1333-8.

73. Martin CE, Longinaker N, Terplan M. Recent trends in treatment admissions for prescription opioid abuse during pregnancy. J Subst Abus Treat. 2015;48(1):3742.

74. Whiteman VE, Salemi JL, Mogos MF, et al. Maternal opioid drug use during pregnancy and its impact on perinatal morbidity, mortality, and the costs of medical care in the United States. J Pregnancy.

2014;2014:906723.

75. Fullerton CA, Kim M, Thomas CP, et al. Medicationassisted treatment with methadone: assessing the evidence. Psychiatr Serv. 2014;65(2):146-57. 
76. Mattick RP, Breen C, Kimber J, et al. Buprenorphine maintenance versus placebo or methadone maintenance for opioid dependence (review). The Cochrane Collaboration, published in The Cochrane Library. 2014, Issue 2.

77. Jones H, Deppen K, Hudak ML, et al. Clinical care for opioid-using pregnant and postpartum women: the role of obstetric providers. Am J Obstet Gynecol. 2014;210(4):302-10.

78. Lund IO, Fischer G, Welle-Strand GK, et al. A comparison of buprenorphine + naloxone to buprenorphine and methadone in the treatment of opioid dependence during pregnancy: maternal and neonatal outcomes. Subst Abuse. 2013;7:61-74.

79. Debelak K, Morrone WR, O'Grady KE, et al. Buprenorphine + naloxone in the treatment of opioid dependence during pregnancy-initial patient care and outcome data. Am J Addict. 2013;22(3):252-4.

80. Wiegand SL, Stringer EM, Stuebe AM, et al. Buprenorphine and naloxone compared with methadone treatment in pregnancy. Obstet Gynecol. 2015;125(2):363-8.

81. Mozurkewich EL, Rayburn WF. Buprenorphine and methadone for opioid addiction during pregnancy. Obstet Gynecol Clin N Am. 2014;41(2):241-53.

82. Hudak ML, Tan RC, Committee on Drugs, et al. Neonatal drug withdrawal. Pediatrics. 2012;129(2):e54060 .

83. Kocherlakota P. Neonatal abstinence syndrome. Pediatrics. 2014;134(2):e547-61.

84. Wachman EM, Hayes MJ, Brown MS, et al. Association of OPRM1 and COMT single-nucleotide polymorphisms with hospital length of stay and treatment of neonatal abstinence syndrome. JAMA.

2013;309(17):1821-7.

This study highlights value of pharmacogenomics research and affirms the importance of OPRM1 gene in opioid addiction and neonatal abstinence syndrome (NAS). Investigators found variants in the OPRM1 and COMT genes were associated with shorter hospital stays and less need for treatment among infants with NAS.

85. Wachman EM, Hayes MJ, Lester BM, et al. Epigenetic variation in the mu-opioid receptor gene in infants with neonatal abstinence syndrome. J Pediatr. 2014;165(3):472-8.

86.• Haug NA, Duffy M, McCaul ME. Substance abuse treatment services for pregnant women: psychosocial and behaviorgdal approaches. Obstet Gynecol Clin N Am. 2014;41(2):267-96.

This article summarizes evidence-based psychosocial and behavioral interventions for the treatment of pregnant drug dependent women.

87. American Society of Addiction Medicine. Public policy statement on women, alcohol and other drugs, and pregnancy. Chevy Chase: American Society of Addiction Medicine; 2011.

88. Terplan M, Lui S. Psychosocial interventions for pregnant women in outpatient illicit drug treatment programs compared to other interventions. Cochrane Database Syst Rev. 2007;4, CD006037.

89. Higgins ST, Washio Y, Lopez AA, et al. Examining two different schedules of financial incentives for smoking cessation among pregnant women. Prev Med. 2014;68:51-7.

90. State Policies in Brief. Substance abuse during pregnancy. Guttmacher Institute. 2015. Accessed 20 May 2015. Available from: http://www.guttmacher. org/statecenter/spibs/spib_SADP.pdf.

91. Hendricks $M$, Testa RJ. Model for understanding risk and resiliency in transgender and gendernonconforming individuals. Prof Psychol Res Pract. 2012;43(5):460-7.

92. Stroumsa D. The state of transgender health care: policy, law, and medical frameworks. Am J Public Health. 2014;104(3):e31-8.

93. Testa RJ, Sciacca LM, Wang F, et al. The effects of violence on transgender people. Prof Psychol Res Pract. 2012;43(5):452-9.

94. Santos GM, Rapues J, Wilson EC, et al. Alcohol and substance use among transgender women in San Francisco: prevalence and association with human immunodeficiency virus infection. Drug Alcohol Rev. 2014;33(3):287-95.

95. Rowe C, Santos GM, McFarland W, et al. Prevalence and correlates of substance use among trans female youth ages 16-24 years in the San Francisco Bay Area. Drug Alcohol Depend. 2015;147:160-6.

96. Stevens S. Meeting the substance abuse treatment needs of lesbian, bisexual and transgender women: implications from research to practice. Subst Abuse Rehabil. 2012;3 Suppl 1:27-36.

97. Flentje A, Heck NC, Sorensen JL. Characteristics of transgender individuals entering substance abuse treatment. Addict Behav. 2014;39(5):969-75.

98. Nuttbrock LA. Culturally competent substance abuse treatment with transgender persons. J Addict Dis. 2012;31(3):236-41.

99. Testa RJ, Habarth J, Peta J, et al. Development of the gender minority stress and resilience measure. Psychology of Sexual Orientation and Gender Diversity. 2014.

100.• Bockting W, Knudson G, Goldberg J. Counselling and mental health care of transgender adults and loved ones. Vancouver Coastal Health-Transgender Health Program. Vancouver: The Haworth Press, Inc; 2006.

This is a comprehensive protocol addressing transgender mental health that serves as an important resource for clinicians working with this population. 